EPiC Series in Engineering
Volume 3, 2018, Pages 419-427
HIC 2018. 13th International
Conference on Hydroinformatics

\title{
Vegetation Change Analyses Considering Climate Variables and Anthropogenic Variables in the Three-River Headwaters Region
}

\author{
Chen Chen ${ }^{1 *}$, Tiejian $\mathrm{Li}^{1,2 \dagger}$, Jiaye $\mathrm{Li}^{1}$, Wang $\mathrm{Fu}^{1}$, and Guangqian Wang ${ }^{1,2,3}$ \\ ${ }^{1}$ State Key Laboratory of Hydroscience and Engineering, Tsinghua University, Beijing, China \\ ${ }^{2}$ State Key Laboratory of Plateau Ecology and Agriculture, Qinghai University, Xining, China \\ ${ }^{3}$ Sanjiangyuan Collaborative Innovation Center, Qinghai University, Xining, China \\ chenchen14@mails.tsinghua.edu.cn, litiejian@tsinghua.edu.cn, li- \\ jy13@mails.tsinghua.edu.cn, fuw14@mails.tsinghua.edu.cn, dhhwgq@mail.tsinghua.edu.cn
}

\begin{abstract}
In the terrestrial biosphere, vegetation plays vital roles in providing food and habitats for humankind and animals. In general, vegetation activity is influenced by both climate drivers and anthropogenic drivers, and studies have tried to disentangle contributions of these multiple variables from each other. However, it remains largely unclear how climatic and anthropogenic effects work together to impact on vegetation dynamics. In this study, we analyzed the vegetation change from 1995 to 2014 in the Three-River Headwaters Region (TRHR) using Normalized Difference Vegetation Index (NDVI). We applied partial correlation analyses to discriminate the contributions of climate variables and anthropogenic variables. The result indicates that the TRHR experiences a slightly greening trend from 1995 to 2014. The primary climatic driving factor is temperature for the southeast and south parts of the TRHR, precipitation in the west part, and a combination of precipitation, temperature and cloud cover for northeast part. The interaction between precipitation and cloud cover, precipitation and grazing activity, temperature and population activity, contribute to vegetation growth. The relationship between vegetation activity and the driving factors are evolving towards the direction which vegetation favors for the past two decades.
\end{abstract}

\section{Introduction}

In the terrestrial biosphere, vegetation plays vital roles in providing food and habitats for humankind and animals (De Jong et al., 2013). NDVI is a remote sensed proxy for vegetation cover and

* Created the first draft of this paper

${ }^{\dagger}$ Corresponding author

G. La Loggia, G. Freni, V. Puleo and M. De Marchis (eds.), HIC 2018 (EPiC Series in Engineering, vol. 3), pp. $419-427$ 
photosynthetic capacity, and has been commonly used in vegetation-change studies (Wu et al., 2015; Peng et al., 2013). Vegetation change, including greening trend and browning trend, has been reported in global, country and regional scales (Verbyla, 2008; Piao et al., 2015; Zhu et al., 2016).

Vegetation activity is influenced by both climate factors and anthropogenic factors. In general, climate factors include precipitation, temperature and solar radiation, which entangle and interact with each other, imposing complex and varying limitations on vegetation activity (Nemani et al., 2003). Vegetation, whose structural attributes such as albedo, roughness length, leaf area index (LAI), and distribution, will affect the regional climate by regulating turbulent fluxes (Pitman, 2003), making it ambiguous to grasp the whole map of climate-vegetation interaction. Apart from climate factors, vegetation change may induced by anthropogenic drivers such as land use change, fertilization, irrigation, urbanization, and grazing, among others. (Díaz et al., 2007; Neigh et al., 2008; Wu et al., 2015; Zhu et al., 2016).

Recently, studies have tried to disentangle contributions of multiple climate and anthropogenic drivers from each other. Liang et al. applied a residual analysis trend method to distinguish effects of precipitation, temperature, the excessive exploitation of water resource, oil and natural gas extraction in Central Asia (Jiang et al., 2017). Liu et al. analyzed global NDVI trends correlations with climate and human factors using Theil-Sen median slope method and Human Influence Index (HII) (Liu et al., 2015). For rangeland ecosystem, grazing effect is one of the most important anthropogenic drivers and has been assessed in some studies (Walker et al., 2009; Archer, 2004). However, it still remains unclear how climate and anthropogenic effects work together to impact on vegetation dynamics, and their separated contributions are largely unknown.

In this study, we applied partial correlation analyses to disentangle the contributions of climate variables (precipitation, temperature and cloud cover) and anthropogenic variables (grazing effect and population pressure) in the TRHR. Firstly, we analyzed temporal and spatial vegetation change trend from 1995 to 2014. Then we made use of NDVI data from GIMMS3g NDVI dataset, precipitation data from Climate Hazards Group Infrared Precipitation with Stations (CHIRPS), temperature data from ERA-Interim, cloud cover data from Climate Research Unit (CRU, version TS 4.01), livestock production and population data from Qinghai Statistical Almanacs to conduct the analyses. We endeavored to figure out the interactions within climate variables, and between climate variables and anthropogenic variables. Finally, we pointed out the changing relationship between vegetation activity and the driving factors.

\section{Material and methods}

\subsection{Data}

NDVI. NDVI used in this study is NDVI3g from the Global Inventory Monitoring and Modelling Studies (GIMMS) group derived from the NOAA/AVHRR land data set. The dataset spans from July 1981 to December 2015 at a spatial resolution of $0.083^{\circ}$ and 15 -day interval (Tucker et al., 2005).

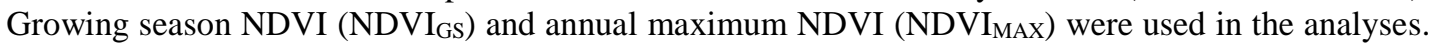
In this study, growing season is defined as the period from May to September. $\mathrm{NDVI}_{\mathrm{GS}}$ and $\mathrm{NDVI}_{\mathrm{MAX}}$ for the TRHR and counties were extracted from pixels within the region and counties.

Climate data. The climate data used in this study, including precipitation, temperature and cloud cover, are from CHIRPS, ERA-Interim and CRU TS 4.01. Monthly CHIRPS product is developed by Climate Hazards Group and has a resolution of $0.05^{\circ}$ from 1981 to real time. ERA-Interim is a global atmosphere reanalysis from 1979 to real time, and we made use of 2 meter surface temperature of monthly means whose resolution is $0.125^{\circ}$. CRU TS 4.01 is interpolated from over 4000 meteorological 
stations with spatial autocorrelation functions, and has a resolution of $0.5^{\circ}$ (Harris et al., 2014). Climate data from 18 local meteorological stations were also used to test the accuracy of the climate datasets.

Livestock and population. Livestock data (beef and mutton production) and population data from 1995 to 2014 are acquired from records of Qinghai Statistical Almanacs.

\subsection{Methods}

Partial correlation analyses. The function of partial correlation analyses is to find the correlation between two variables eliminating the effects of other variables (Garrett and Woodworth, 1971). In general, the partial correlation coefficient can be computed as:

$R_{12,34 \ldots n}=\frac{R_{12,34 \ldots(n-1)}-R_{1 n, 34 \ldots(n-1)} R_{2 n, 34 \ldots(n-1)}}{\sqrt{1-R_{1 n, 34 \ldots(n-1)}^{2}} \sqrt{1-R_{2 n, 34 \ldots(n-1)}^{2}}}$

Where $R_{12,34 \ldots n}$ refers to partial correlation coefficient between variables 1 and 2 while removing the effect of variables $3,4, \ldots, n$.

In this study, we conducted partial correlation analyses between $\mathrm{NDVI}_{\mathrm{GS}}$ and one driving variable, controlling the other 4 variables. We tried to disentangle the coordination effects between different variables in doing partial correlation analyses.

\section{Results and discussion}

\subsection{Spatiotemporal change in vegetation}

We applied the linear regression method to analyze the regional vegetation change in the TRHR from 1995 to 2014. Overall, $\mathrm{NDVI}_{\mathrm{GS}}$ in the TRHR experiences a slightly greening trend $(0.52 \% / 10 \mathrm{a})$ (Figure 1a). This agrees with early studies (Liu et al., 2014; Pan et al., 2017). Specifically, NDVI $\mathrm{GS}_{\mathrm{S}}$ goes through four stages of change. At the first stage, $\mathrm{NDVI}_{\mathrm{GS}}$ increases from 0.349 to 0.382 for the first 6 years, then it decreases from 2000 to 2008. From 2008 to 2010, NDVI $\mathrm{G}_{\mathrm{GS}}$ rises sharply, peaking at 0.395 in 2010 . At the last stage, it drops to 0.363 by 2014 . NDVI $\mathrm{MAX}$ in the TRHR experiences similar trend with $\mathrm{NDVI}_{\mathrm{GS}}$ (Figure 1b).
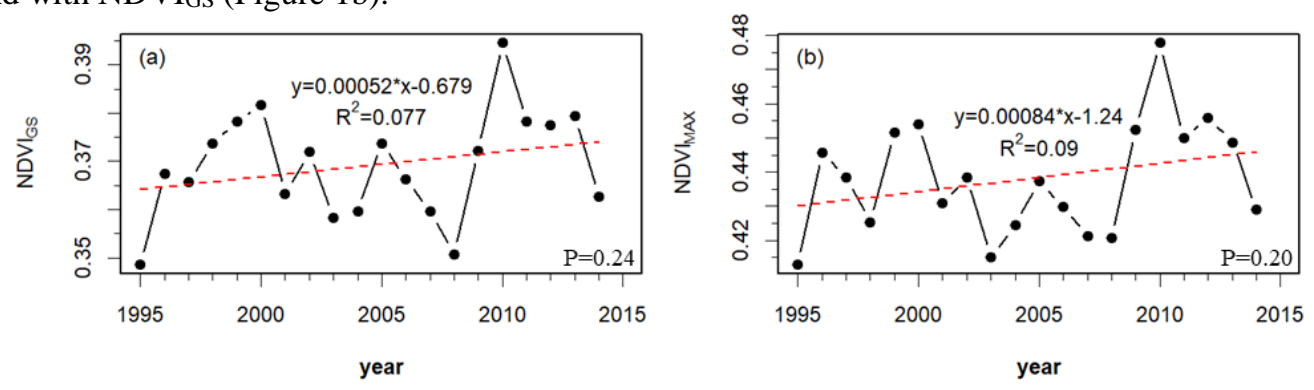

Figure 1: Temporal vegetation change from 1995 to 2014 in the TRHR. a) NDVIGs; b) NDVI $I_{\text {MAX }}$

Secondly, we analyzed the $\mathrm{NDVI}_{\mathrm{GS}}$ trend in each county and in each grid of the TRHR for the same period (from 1995 to 2014). The distribution of greening and browning trend of vegetation is shown in Figure 2. From 1995 to 2014, the areas with browning trend are mainly located in the southeast and south parts of TRHR (Figure 2a), including Yushu County (YS), Nangqeen County (NQ), Tarlag County (DR), Maqeen County (MQ), Baima County (BM), Henan County (HN), Jigzhi County (JZ), Gadee County (GD). The browning trend ranges from $0.2 \% /$ decade in the YS to $2.1 \% /$ decade in the 
GD. By contrast, the areas with greening trend are distributed in the west and northeast parts of the TRHR, including Tanggulashan town (TGLS), Chindu County (CD), Zadoi County (ZAD), Tongren County (TR), Tongde County (TD), Zhidoi County (ZD), Zeekog County (ZK), Xinghai County (XH), Qumarleeb County (QML), Madoi County (MD), Gonghe County (GH), Guide County (GUD), Guinan County (GN), Jianzha County (JZA). The greening trend ranges from $0.5 \% /$ decade in the TGLS to $2.5 \% /$ decade in the JZA. NDVI Gs $_{\text {trend }} 9$ counties out of 22 in the TRHR is significant, and 7 counties shows significant greening trend.

The NDVI ${ }_{\text {GS }}$ trend in grid scale is consistent with that of county scale (Figure 2b). $39.8 \%$ grids experience significant vegetation change from 1995 to 2014, with browning trend located in the southeast and south parts and greening trend located in the northeast and west parts.

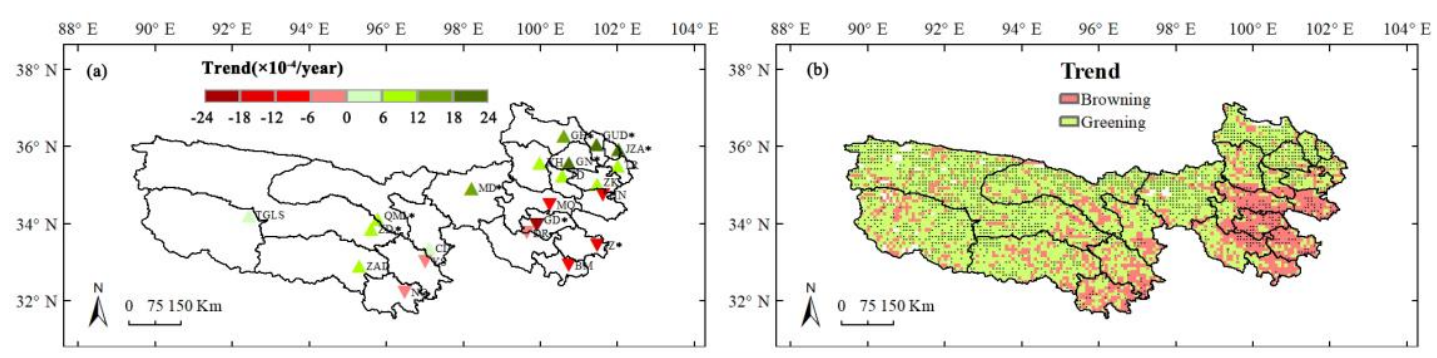

Figure 2: Distribution of vegetation change from 1995 to 2014 in the TRHR. a) county scale, the stars indicate significance at $\mathrm{P}<0.05$; b) grid scale, the black spots indicate significance at $\mathrm{P}<0.05$

\subsection{Discriminating climate and anthropogenic drivers of vegetation change based on partial correlation analyses}

During the past two decades, the climate and anthropogenic variables in the TRHR have experienced significant change (Figure 3), which in return drives the evolution of vegetation. Growing season precipitation (GP), annual livestock production, annual population increase signicant $(\mathrm{P}<0.001)$ in the TRHR, and climate warming is enhanced for the region $(\mathrm{P}=0.08)$. Growing season cloud cover (GC) decreases for the same period, but the trend is not significant $(\mathrm{P}=0.83)$.
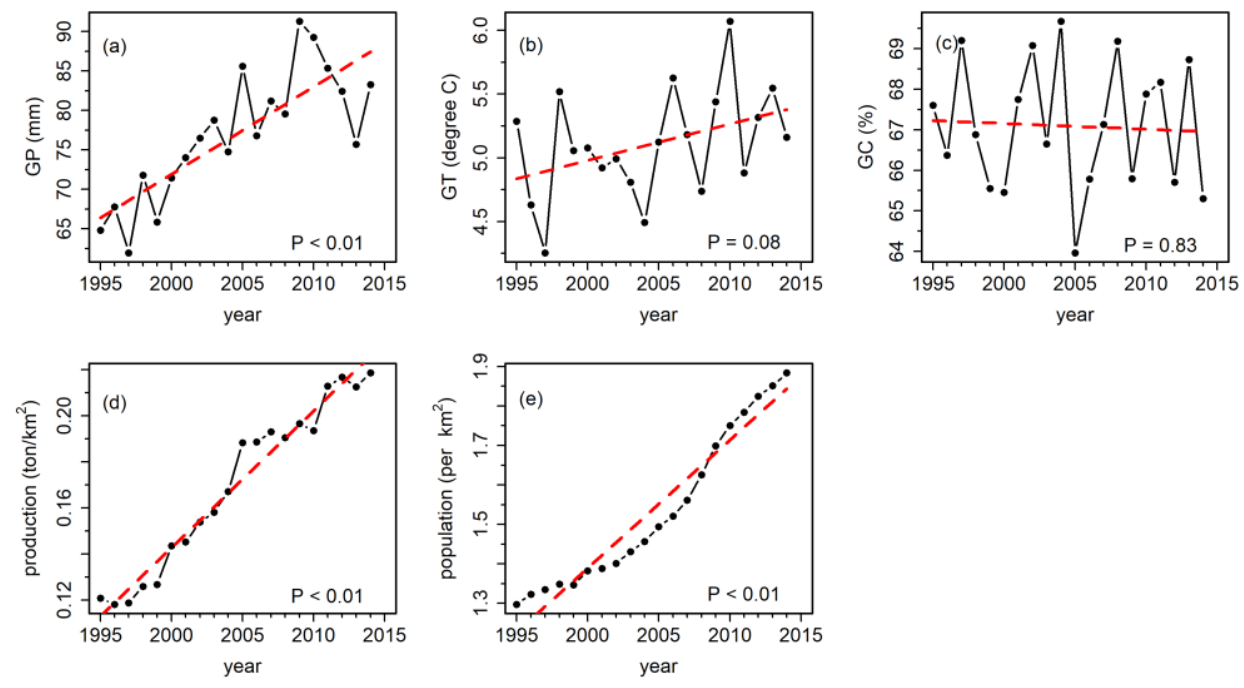

Figure 3: Change of climate and anthropogenic variables in the TRHR from 1995 to 2014. a) GP; b) GT (growing season temperature); c) GC; d) annual livestock production; e) annual population 
To discriminate climate and anthropogenic drivers of vegetation change, we first detrended all variables to focuse on correlations in interannual variablility, and then caculated the partial correlation coefficiency between $\mathrm{NDVI}_{\mathrm{GS}}$ and GP ( $\left.\mathrm{R}_{\mathrm{NDVI}-\mathrm{GP}}\right)$, NDVI and GT $\left(\mathrm{R}_{\mathrm{NDVI}-\mathrm{GT}}\right), \mathrm{NDVI}_{\mathrm{GS}}$ and GC $\left(\mathrm{R}_{\mathrm{NDVI}}\right.$

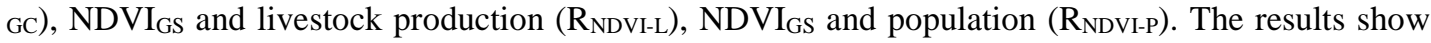
that vegetation is enhanced by climate warming $\left(\mathrm{R}_{\mathrm{NDVI}-\mathrm{GT}}=0.35, \mathrm{P}=0.19\right)$ in the TRHR, whereas it is deteriorated by increasing grazing pressure $\left(\mathrm{R}_{\mathrm{NDVI}-\mathrm{L}}=-0.39, \mathrm{P}=0.14\right)$. Climate warming and increasing grazing pressure drive vegetation to evolve toward opposite directions, in which process the effect of climate warming dominate. Precipitation $\left(\mathrm{R}_{\mathrm{NDVI}-\mathrm{GP}}=0.18, \mathrm{P}=0.50\right)$, cloud cover $\left(\mathrm{R}_{\mathrm{NDVI}-\mathrm{GC}}=-0.19, \mathrm{P}=0.49\right)$ and population $\left(\mathrm{R}_{\mathrm{NDVI}-\mathrm{P}}=0.1, \mathrm{P}=0.72\right)$ show no significant impacts on the greening trend of vegetation in the THRH. The effects of GT, GP, and grazing are supported by early studies (Piao et al., 2014; Cong et al., 2017).

We conducted the same analyses based on county scale. The partial correlation coefficients of $\mathrm{NDVI}_{\mathrm{GS}}$ to the driving factors are shown in Figure 4. The partial correlation coefficients between $\mathrm{NDVI}_{\mathrm{GS}}$ and GP, controlling GT, GC, livestock production and population, show remarkable spatial pattern (Figure 4a). NDVI ${ }_{\mathrm{GS}}$ in the northeast and west part of the TRHR is positively correlated with GP, but the correlation is not significant. NDVI $\mathrm{Gs}_{\mathrm{S}}$ in the southeast part of the TRHR is negatively correlated with GP, and the link is weak $(0.1<\mathrm{P}<0.2)$. The relationship between $\mathrm{NDVI}_{\mathrm{GS}}$ and GT also shows spatial pattern (Figure 4b). A significant positive correlation between $\mathrm{NDVI}_{\mathrm{GS}}$ and GT is found in the southeast and south part of the TRHR, while a weak negative correlation between $\mathrm{NDVI}_{\mathrm{GS}}$ and GT is distributed in the northeast part of the TRHR. The partial correlation between NDVI $\mathrm{Gs}_{\text {and }}$ GC in the northeast, south and west part of the TRHR, is negative, but the correlation is not significant (Figure 4c). The results are consistent with Liu et al.'s (Liu et al., 2014).

(a)

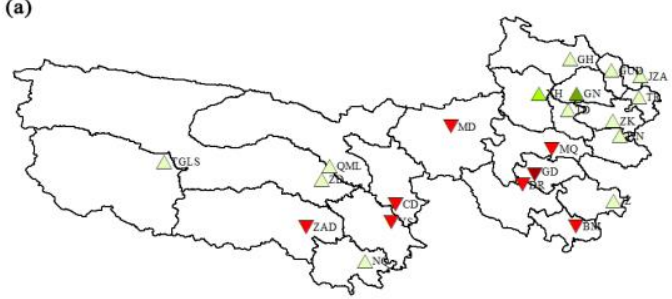

(c)

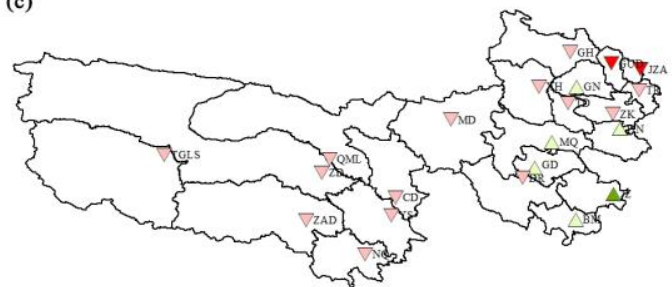

(e)

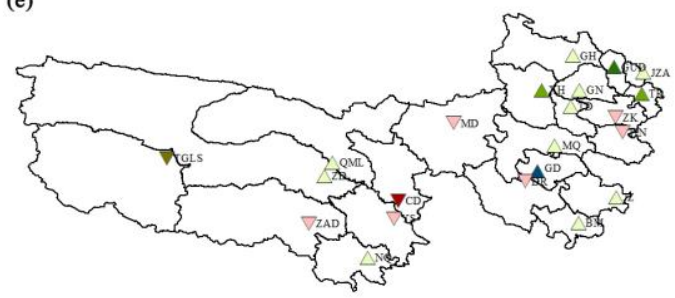

(b)

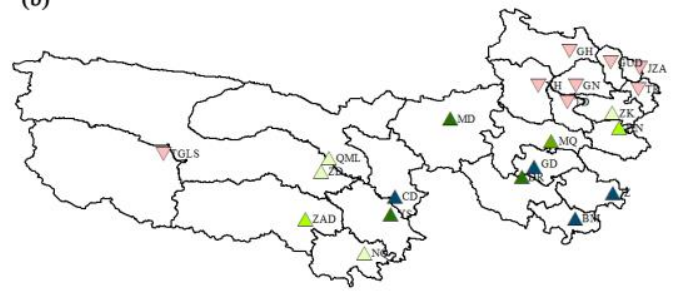

(d)

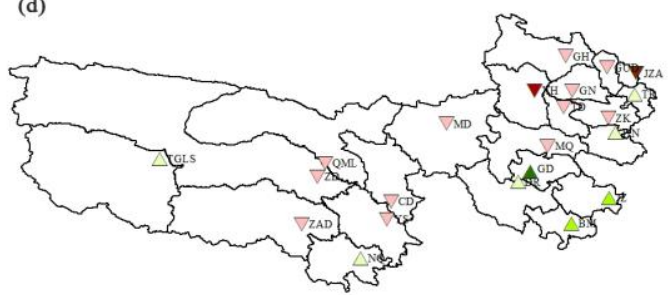

$\mathbf{R}$

$\begin{array}{lllllllllllll}-1 & -.62 & -.50 & -.42 & -.34 & 0 & .34 & .42 & .50 & .62 & 1\end{array}$

Figure 4: Partial correlation coefficients of NDVIGs to the driving factors. a) RNDVI-GP; b) RNDVI-GT; c) RNDVI-GC;

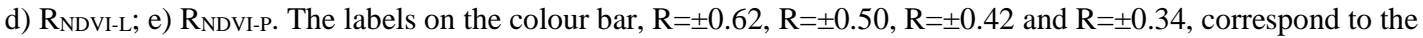
$1 \%, 5 \%, 10 \%$ and $20 \%$ significance levels 
The effects of anthropogenic factors on vegetation variation are complicated. $\mathrm{NDVI}_{\mathrm{GS}}$ in the northeast and west parts of the TRHR is negatively correlated with livestock production, but only JZA and $\mathrm{XH}$ show significant relationship (Figure 4d). It indicates that these counties are faced with grazing pressure. The areas with positive $\mathrm{R}_{\mathrm{NDVI}-\mathrm{L}}$ are located in the southeast part of the TRHR. The relationship between $\mathrm{NDVI}_{\mathrm{GS}}$ and population is more complicated (Figure 4e). $\mathrm{R}_{\mathrm{NDVI}-\mathrm{P}}$ in the CD and TGLS is negative $(\mathrm{P}<0.05)$, while it is positive in the GD and GUD $(\mathrm{P}<0.05)$.

According to previous studies, the climate factor with bigger absolute value of partial correlation coefficient is regarded as the primary climatic driving factor of vegetation change (Peng et al., 2015). We compare the absolute values of $\mathrm{R}_{\mathrm{NDVI}-\mathrm{GP}}, \mathrm{R}_{\mathrm{NDVI}-\mathrm{GT}}$ and $\mathrm{R}_{\mathrm{NDVI}-\mathrm{GC}}$ for each county. The primary climatic driving factor is temperature for the southeast and south parts of the TRHR, and precipitation for the west part. The absolute values of $\mathrm{R}_{\mathrm{NDVI}-\mathrm{GP}} \mathrm{R}_{\mathrm{NDVI}-\mathrm{GT}}$ and $\mathrm{R}_{\mathrm{NDVI}-\mathrm{GC}}$ are close, so vegetation activity in northeast part is driven by a combination of precipitation, temperature and cloud cover.

\subsection{Effects of interactions of climate factors on the correlations between $\mathrm{NDVI}_{\mathrm{GS}}$ and climate factors, $\mathrm{NDVI}_{\mathrm{GS}}$ and anthropogenic factors}

Climate variables and anthropogenic factors might interact with each other to impact on vegetation activity, as the interactions are revealed by many studies ( Peng et al., 2013; Piao et al., 2014; Zhu et al., 2016; Cong et al., 2017; Pan et al., 2017). In this study we analyzed the effects of interactions within climate variables, and between climate variables and anthropogenic variables. The results reveal the possible reasons why $\mathrm{NDVI}_{\mathrm{GS}}$ responses to the driving factors heterogeneously.
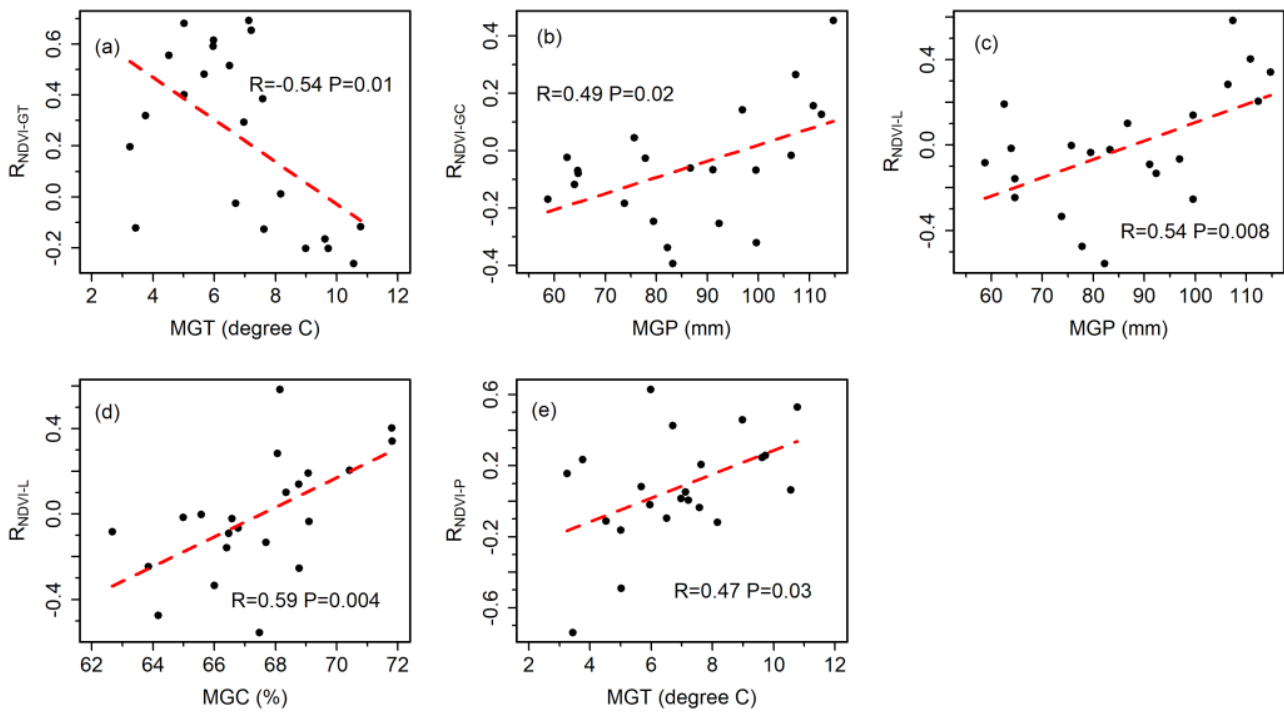

Figure 5: Correlation of partial correlation coefficients to MGT, MGP and mean MGC. MGT, MGP, and MGC are calculated as the mean of 20 years' growing season temperature, precipitation, and cloud cover within a county. Each point represents a county. a) RNDVI-GT to MGT; b) RNDVI-GP to MGC; c) RNDVI-L to MGP; d) RNDVI-L to MGC; e) RNDVI-P to MGT

The partial correlation coefficients of $\mathrm{NDVI}_{\mathrm{GS}}$ to GP response weakly $(\mathrm{P}>0.2)$ to climate factors, namely mean GP (MGP), mean GT (MGT) and mean GC (MGC), indicating that the spatial distribution of $\mathrm{R}_{\mathrm{NDVI}-\mathrm{GP}}$ is largely dominated by precipitation. MGP from 1995 to 2014 decreases from the southeast to the northwest. This explains why vegetation in the northeast and west parts response to GP more sensitively, while it responses negatively in the southeast (Figure $4 a)$. $R_{\text {NDVI-GT }}$ is significant $(R=-0.54$, 
$\mathrm{P}=0.01)$ correlated with MGT (Figure 5a), while weakly correlated with MGP $(\mathrm{R}=0.35, \mathrm{P}=0.11)$ and MGC $(\mathrm{R}=0.34, \mathrm{P}=0.12)$. Climate warming has contributed to the greening trend in the Tibetan Plateau and the TRHR (Piao et al., 2015; Zhu et al., 2016). This is supported by positive $\mathrm{R}_{\mathrm{NDVI} \text {-GT }}$ in most areas of the TRHR (Figure 5a). The negative relationship between NDVI $\mathrm{GS}_{\mathrm{S}}$ and GT could be explained by extreme hot days (Seneviratne et al., 2014; Piao et al., 2014), because MGT in these areas is higher than other parts. The relationship between $\mathrm{R}_{\mathrm{NDVI} I \mathrm{GC}}$ and MGP is significant (Figure $5 \mathrm{~b}, \mathrm{R}=0.49, \mathrm{P}=0.02$ ), while it is weak between $\mathrm{R}_{\mathrm{NDVI}-\mathrm{GC}}$ and MGT $(\mathrm{R}=-0.24, \mathrm{P}=0.27), \mathrm{R}_{\mathrm{NDVI}-\mathrm{GC}}$ and MGC $(\mathrm{R}=-0.41, \mathrm{P}=0.06)$. The result indicates that the effect of GC on vegetation is regulated by GP, and vegetation growth favours cloudy and wet weather during growing season.

The coordination of anthropogenic variables and climate variables might drive vegetation towards favourable direction. The coexistence of cloudy and wet weather promise vegetation to flourish, thus making it possible for the vegetation to raise more livestock. The mechanism is supported by positive correlation between $\mathrm{R}_{\mathrm{NDVI}-\mathrm{L}}$ and MGP (Figure $5 \mathrm{c}, \mathrm{R}=0.54, \mathrm{P}=0.008$ ), $\mathrm{R}_{\mathrm{NDVI}-\mathrm{L}}$ and MGC (Figure $5 \mathrm{~d}$, $\mathrm{R}=0.59, \mathrm{P}=0.004)$. Moreover, vegetation is enhanced by warm weather in most areas of the TRHR, and population pressure on vegetation is relieved by climate warming. This is confirmed by positive correlation between $\mathrm{R}_{\mathrm{NDVI}-\mathrm{P}}$ and MGT (Figure 5e, $\mathrm{R}=0.47, \mathrm{P}=0.03$ ).

For the past two decades, precipitation and temperature increase significantly in the TRHR, and cloud cover decreases slightly (Figure 3 ). The interaction between precipitation (increased) and cloud cover (decreased) contribute to vegetation growth (Figure 5b). Moreover, although grazing and population pressure make vegetation deteriorate $\left(\mathrm{R}_{\mathrm{NDVI}-\mathrm{L}}<0\right)$, the interactions between precipitation (increased) and grazing activity (Figure 5c), temperature (increased) and population activity (Figure 5e), offset the deterioration. So climate factors largely dominate in vegetation change from 1995 to 2014, while anthropogenic factors contribute less.

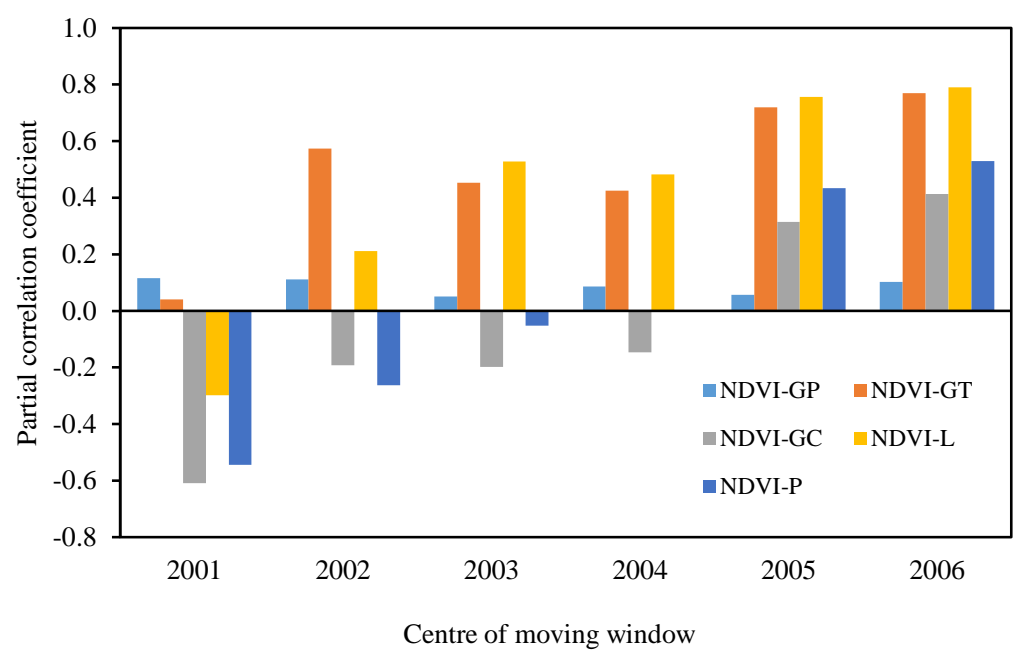

Figure 6: Changes in the partial correlation coefficients between NDVI $\mathrm{GS}_{\mathrm{G}}$ and GP, NDVI $\mathrm{GS}$ and GT, NDVI $\mathrm{GS}_{\mathrm{GS}}$ and $\mathrm{GC}, \mathrm{NDVI}_{\mathrm{GS}}$ and livestock production, $\mathrm{NDVI}_{\mathrm{GS}}$ and population by applying 15 -year moving windows. The $\mathrm{x}$ axis is the centre of the 15 -year moving window

\subsection{Changing relationship between vegetation activity and its driving factors}

We explore the dynamic relationships between vegetation activity and the driving variables by applying partial correlation analyses based on 15-year moving windows (Figure 6). The results reveal 
that the relationship between $\mathrm{NDVI}_{\mathrm{GS}}$ and $\mathrm{GT}, \mathrm{NDVI}_{\mathrm{GS}}$ and $\mathrm{GC}, \mathrm{NDVI}_{\mathrm{GS}}$ and livestock production, $\mathrm{NDVI}_{\mathrm{GS}}$ and population, are strengthened for the past two decades (from 1995 to 2014) in the TRHR. The relationship between $\mathrm{NDVI}_{\mathrm{GS}}$ and GP, however, doesn't change significantly for the same period. The results also indicate that climate change is favoured by vegetation activity for the past two decades, which are consistent with previous studies (Piao et al., 2015).

\section{Conclusion}

In this study, we analyzed spatiotemporal change in vegetation using linear regression method, and applied partial correlation analyses to disentangle the contributions of climate variables and anthropogenic variables in the TRHR. The result indicates that the TRHR experiences a slightly greening trend from 1995 to 2014 . The areas with browning trend are mainly located in the southeast and south parts of TRHR, while the areas with greening trend are distributed in the west and northeast parts of the TRHR. The partial correlation analyses reveal that the primary climatic driving factor is temperature for the southeast and south parts of the TRHR, precipitation for the west part, and a combination of precipitation, temperature and cloud cover for northeast part. The interaction between precipitation and cloud cover, precipitation and grazing activity, temperature and population activity, contribute to vegetation growth. The relationship between vegetation activity and the driving factors are evolving towards the direction which vegetation favors for the past two decades.

\section{References}

Archer, E.R.M., 2004. Beyond the "climate versus grazing" impasse: using remote sensing to investigate the effects of grazing system choice on vegetation cover in the eastern Karoo. Journal of Arid Environments, 57(3): 381-408.

Cong, N. et al., 2017. Varying responses of vegetation activity to climate changes on the Tibetan Plateau grassland. International Journal of Biometeorology, 61(8): 1433-1444.

De Jong, R., Schaepman, M.E., Furrer, R., de Bruin, S. and Verburg, P.H., 2013. Spatial relationship between climatologies and changes in global vegetation activity. Global Change Biology, 19(6): 19531964.

Díaz, S. et al., 2007. Plant trait responses to grazing - a global synthesis. Global Change Biology, 13(2): 313-341.

Garrett, H.E. and Woodworth, R.S., 1971. Statistics in psychology and education. David McKay, New York, 505pp.

Harris, I., Jones, P.D., Osborn, T.J. and Lister, D.H., 2014. Updated high-resolution grids of monthly climatic observations - the CRU TS3.10 Dataset. International Journal of Climatology, 34(3): 623-642.

Jiang, L., Jiapaer, G., Bao, A., Guo, H. and Ndayisaba, F., 2017. Vegetation dynamics and responses to climate change and human activities in Central Asia. Science of the Total Environment, 599: 967980.

Liu, X. et al., 2014. Spatiotemporal changes in vegetation coverage and its driving factors in the Three-River Headwaters Region during 2000-2011. Journal of Geographical Sciences, 24(2): 288-302.

Liu, Y., Li, Y., Li, S. and Motesharrei, S., 2015. Spatial and temporal patterns of global NDVI trends: correlations with climate and human factors. Remote Sensing, 7(10): 13233-13250.

Neigh, C., Tucker, C. and Townshend, J., 2008. North American vegetation dynamics observed with multi-resolution satellite data. Remote Sensing of Environment, 112(4): 1749-1772.

Nemani, R.R. et al., 2003. Climate-driven increases in global terrestrial net primary production from 1982 to 1999 . Science, 300(5625): 1560-1563. 
Pan, T., Zou, X., Liu, Y., Wu, S. and He, G., 2017. Contributions of climatic and non-climatic drivers to grassland variations on the Tibetan Plateau. Ecological Engineering, 108: 307-317.

Peng, J., Li, Y., Tian, L., Liu, Y. and Wang, Y., 2015. Vegetation dynamics and associated driving forces in eastern china during 1999-2008. Remote Sensing, 7(10): 13641-13663.

Peng, S. et al., 2013. Asymmetric effects of daytime and night-time warming on Northern Hemisphere vegetation. Nature, 501(7465): 88-92.

Piao, S. et al., 2014. Evidence for a weakening relationship between interannual temperature variability and northern vegetation activity. Nature Communications, 5: 5018.

Piao, S. et al., 2015. Detection and attribution of vegetation greening trend in China over the last 30 years. Global Change Biology, 21(4): 1601-1609.

Pitman, A.J., 2003. The evolution of, and revolution in, land surface schemes designed for climate models. International Journal of Climatology, 23(5): 479-510.

Seneviratne, S.I., Donat, M.G., Mueller, B. and Alexander, L.V., 2014. No pause in the increase of hot temperature extremes. Nature Climate Change, 4(3): 161-163.

Tucker, C.J. et al., 2005. An extended AVHRR 8-km NDVI dataset compatible with MODIS and SPOT vegetation NDVI data. International Journal of Remote Sensing, 26(20): 4485-4498.

Verbyla, D., 2008. The greening and browning of Alaska based on 1982-2003 satellite data. Global Ecology and Biogeography, 17(4): 547-555.

Walker, D.A. et al., 2009. Spatial and temporal patterns of greenness on the Yamal Peninsula, Russia: interactions of ecological and social factors affecting the Arctic normalized difference vegetation index. Environmental Research letters, 4(0450044): 045004.

$\mathrm{Wu}, \mathrm{D}$. et al., 2015. Time-lag effects of global vegetation responses to climate change. GLOBAL CHANGE BIOLOGY, 21(9): 3520-3531.

Zhu, Z. et al., 2016. Greening of the Earth and its drivers. Nature Climate Change, 6(8): 791-795. 